insensitive action of C-fibre input in the rat spinal cord. Neurosci Lett 1986; 64: 221-5.

5 Woolf CJ. Recent advances in pathophysiology of acute pain. Br J Anaesth 1989; 63: 139-46.

6 Wall $P D$. The prevention of postoperative pain (Editorial). Pain 1988; 33: 289-90.

7 Dahl JB, Kehlet $H$. The value of pre-emptive analgesia in the treatment of postoperative pain. $\mathrm{Br} \mathrm{J}$ Anaesth 1993; 70 434-9.

8 Katz J, Kavanagh BP, Sandler $A N$, et al. Preemptive analgesia: clinical evidence of neuroplasticity contributing to postoperative pain. Anesthesiology 1992; 77: 439-46.

9 Abram SE, Yaksh TL. Morphine, but not inhalation anesthesia, blocks post-injury facilitation. The role of preemptive suppression of afferent transmission. Anesthesiology 1993; 78: 713-21.

10 Smith CM, Guralnick MS, Gelfand MM, Jeans $M E$. The effects of transcutaneous electrical nerve stimulation on post-cesarean pain. Pain 1986; 27: 181-93.

\section{Anaesthesia for awake craniotomy}

To the Editor:

Assessment of consciousness and motor function is important in many neurosurgical procedures. We report a case where general anaesthesia without tracheal intubation was induced for craniotomy, the patient was awakened, minimal changes in speech and vision were ascertained, and the patient was then re-anaesthetized for skull closure.

This patient is a $28-y \mathrm{r}$-old $60 \mathrm{~kg}$ woman referred for resection ependymoma of the motor and speech cortex. Cortical mapping was planned to identify areas at risk and to preserve as much normal tissue as possible, requiring the patient to be awake and alert with discriminatory functions intact.

At the preoperative, the patient understood the value of being awake for cerebral protection but was hesitant to being conscious for the opening of her skull, but she agreed to the following procedure.

After ascertaining a therapeutic dilantin level (22.6 $\mathrm{mg} \cdot \mathrm{ml}^{-1}$ ), she received midazolam $1.5 \mathrm{mg} i v$. Anaesthesia was induced with sufentanil, $20 \mu \mathrm{g}$ and propofol $100 \mathrm{mg}$ bolus, after lidocaine $25 \mathrm{mg}$. The lungs were easily ventilated by mask. An $8.0 \mathrm{~mm}$ nasal airway was shortened to $22 \mathrm{~cm}$, placed in the right naris, and connected to the breathing circuit by a \#7 endotracheal tube connector. With this arrangement, we were able to ventilate the lungs by closing the mouth and applying $20 \mathrm{mmHg}$ to the bag. After spontaneous respiration resumed, a propofol infusion was titrated at $7 \mathrm{mg} \cdot \mathrm{kg}^{-1} \cdot \mathrm{hr}^{-1}$ and supplemented with $60 \% \mathrm{~N}_{2} \mathrm{O} / \mathrm{O}_{2}$. Bupivacaine was injected in the skull prior to tongs placement and skin incision. Ability to ventilate was checked again after she was placed in Mayfield tongs with her head in the semi-lateral position. Spontaneous respiration was maintained with $\mathrm{SpO}_{2}$ of $100 \%$ and $\mathrm{PETCO}_{2}<55 \mathrm{mmHg}$.

The case proceeded without incident for four hours. At the surgeon's request, the propofol infusion and nitrous oxide were discontinued. The patient awoke seven minutes later and answered questions appropriately. She identified areas of cortical stimulation, changes in conjugate eye motion, and was aware of mild degrees of dysarthria which resolved with the cessation of stimuli. Very small incremental doses of sufentanil $20 \mu \mathrm{g}$ and midazolam $1.0 \mathrm{mg}$ were used to increase her comfort during the four hours that she remained awake.

The only unexpected event was a three-minute episode of non-thermogenic shivering upon awakening which resolved without treatment. Focal seizures occurred several times with cortical stimulation and resolved with discontinuation of the stimulation. Following tumour removal, she was re-anaesthetized at her request for skull closure using propofol, $\mathrm{N}_{2} \mathrm{O}, \mathrm{O}_{2}$, and sufentanil. The total duration of the case was $11 \mathrm{hr}$.

We were pleased with the ease of providing an effective anaesthetic for a difficult problem. Potential difficulties considered included vomiting, grand mal seizures, or a psychotic episode. Fortunately, this young woman did well and was discharged with no residual effects after seven days. She remains symptom free.

F.R. Weiss MD

R. Schwartz MD

Department of Anesthesiology

University of South Alabama

Mobile, Al.

\section{Endotracheal tube fires}

To the Editor:

Numerous protocols for the management of endotracheal tube fires have recommended stopping ventilation and disconnecting the endotracheal tube at the $Y$ connector. ${ }^{1-3}$ Based on my own experience, and that of others gained during demonstrations of laser-induced endotracheal tube fires, I feel that these goals can best be met when using a circle system by disconnecting the anaesthesia circuit at both the inspiratory and expiratory valves. This one 
step immediately stops ventilation and fresh gas supply to the burning tube, be it still in the patient or, having been removed by the surgeon, free in the operating room. To disconnect at the anesthesia $\mathrm{Y}$ increases the risk of burns to personnel, takes more time in that it is a second step, may be beyond the anaesthetist's reach, and may not solve the problem.

Glenn E. Deboer MD

The Cleveland Clinic Foundation

Department of General Anesthesiology-M26

9500 Euclid Avenue

Cleveland, Ohio 44195

\section{REFERENCES}

1 Sasis $M$. Anesthesia for laser surgery, Anesthesiol Clin 1984; 21.

2 Health Devices 1990; 19: 111-2.

3 Krawtz S, Mehta AC, Wiedemann HP, DeBoer G, Schoepf KD, Tomaszewski $M Z$. Nd-YAG laser-induced endobronchial burn: management and long-term follow-up. Chest 1989; 95: 916-8.

\section{Combined loss of resistance- free flow hanging drop technique for spinal anaesthesia}

To the Editor:

We were encouraged by a recent article on hypobaric lidocaine ${ }^{\prime}$ and decided to comment on our own experience with hypobaric tetracaine.

Forty ASA physical status I or II patients scheduled for elective perirectal surgery were placed, initially, in either the prone jack-knife position (Group 1, $n=20$ ) or the lateral recumbent position (Group 2, $n=20$ ) for spinal hypobaric anaesthesia. All lumbar punctures (LP) were performed using Taylor's approach ${ }^{2,3}$ at the $\mathrm{L}_{5}-\mathrm{S}_{1}$ interspace using a Pharmaseal ${ }^{\circledR}$ spinal anaesthesia tray (Baxter Healthcare Corp., USA). A combined loss of resistance (LOR) to air and free flow hanging drop technique (FFHD) using the STYLEX ${ }^{\circledR}$ plastic syringe detected the epidural and subarachnoid spaces, respectively, in all but three (Group 1) patients. Prior to surgery, all patients placed themselves in the prone jack-knife position, with head down $20^{\circ}$ from horizontal. After surgery they were transported, supine, to the recovery room. Hypobaric tetracaine $1.0-1.5 \mathrm{~mL}$ (Niphanoid ${ }^{\circledR}$ crystals, $0.4 \%$ in sterile water, specific gravity 1.0020 , baricity
0.9951 via sterile water calibration with refractometer at $37^{\circ} \mathrm{C}$ ) was injected slowly $(\leq 5 \mathrm{sec})$ after evidence of cerebrospinal fluid (CSF) free flow through the needle hub. A 22- or 25-gauge 3.5 inch Becton-Dickinson Yale ${ }^{\circledR}$ spinal needle (Rutherford, NJ., USA) was used without four quadrant aspiration or barrotage. ${ }^{3,4}$ In three out of the 20 in Group 1, CSF had to be aspirated from 25-gauge needles to establish subarachnoid entry, ${ }^{5}$ even though, epidural LOR to air was apparent. This method was used because reduced CSF pressure ${ }^{3}$ in this position impeded free flow of CSF through the 25-gauge needle. Free flow using the 22-gauge needles was unhampered, irrespective of initial positioning. No patients developed postoperative headaches, intra/postoperative hypotension or hypoxaemia $\left(\mathrm{SaO}_{2}<90 \%, \mathrm{FIO}_{2} 0.21\right)$. All patients had selective sacral blocks as evidenced by lack of anal sphincter tone and absence of motor weakness $\left(\mathrm{L}_{1}-\mathrm{S}_{1}\right)$.

The LOR-FFHD approach simulates conventional epidural techniques ${ }^{3}$ except that the spinal needle is attached to the plastic syringe. As the bevel is directed towards the midline, LOR to air is checked repeatedly as it nears the ligamentum flavum. Upon penetration of the ligamentum flavum, a subtle loss of resistance is perceived as the syringe plunger abruptly descends one or two graduations $(0.1-0.2 \mathrm{~mL})$. The synringe is immediately detached from the needle hub and checked for CSF free flow. The spinal needle is then cautiously advanced in tripod fashion, until a distinct pop is felt with free flow of CSF seen "hanging" to the needle hub. The syringe is then reattached with the requisite dose deposited into the subarachnoid space. The block is usually established within seconds as evidenced by loss of anal sphincter tone.

The LOR-FFHD technique allows for controlled proprioception in the approach to the ligamentum flavum and dura. However, in the prone jackknife position, where free flow is limited by CSF pressure, ${ }^{3}$ the use of 25 gauge or smaller spinal needles may require careful aspiration for CSF detection despite epidural space identification. This technique may prove helpful in the difficult and/or failed spinal or subarachnoid puncture above the termination of the spinal cord. In contrast to Bodily's study, ${ }^{1}$ selective hypobaric anaesthesia can be attained with lower volumes $(1-1.5 \mathrm{~mL})$ at lower baricities $(0.9951$ vs 0.9985$)$ and at lower spinal levels $\left(\mathrm{L}_{5}-\mathrm{S}_{1}\right.$ vs $\left.\mathrm{L}_{3-4}\right)$ without physiological trespass.

\section{B.P. Gallacher MD FRCPC \\ Riyadh, Saudi Arabia}

\section{REFERENCES}

1 Bodily MN, Carpenter RL, Owens BD. Lidocaine 0.5\% spinal anaesthesia: a hypobaric solution for short stay perirectal surgery. Can J Anaesth 1992; 39: 770-3. 